\section{REVIEW ARTICLE}

\author{
A.C. Miracle \\ M.A. Fox \\ R.N. Ayyangar \\ A. Vyas \\ S.K. Mukherji \\ D.J. Quint
}

\title{
Imaging Evaluation of Intrathecal Baclofen Pump-Catheter Systems
}

SUMMARY: ITB pumps are widely used in the treatment of intractable spasticity for many clinical indications, including cerebral palsy and spinal cord injury. High-dose intrathecal administration places the patient at significant risk for withdrawal in the event of device malfunction, necessitating rapid and complete evaluation of the pump-catheter system. This article reviews the approach to imaging evaluation of ITB pump-catheter systems, with specific emphasis on radiography, fluoroscopy, CT, and nuclear scintigraphy.

ABBREVIATIONS: AP = anteroposterior; DTPA = diethylene-triamine pentaacetic acid; GABA = gamma-aminobutyric acid; ${ }^{111} \mathrm{In}=$ Indium-111; IT = intrathecal; ITB = intrathecal baclofen; Tc99m = technetium-99m

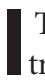
TB therapy, first described in 1984 by Penn and Kroin ${ }^{1}$ for the treatment of spinal cord-origin spasticity, involves continuous delivery of baclofen directly to the pharmacologic site of action in the spinal cord, improving muscle spasm control without the dose-limiting drowsiness associated with high-dose systemic administration of this medication. Dralle et $\mathrm{al}^{2}$ further explored ITB for the treatment of cerebral-origin spasticity in 1985. Since then, implantable intrathecal baclofen delivery systems have been used for multiple indications, including cerebral palsy, ${ }^{3,4}$ spinal cord injury, traumatic or hypoxic-anoxic brain injury, ${ }^{5,6}$ multiple sclerosis, ${ }^{7}$ and stroke. ${ }^{8}$ Aside from these more common indications, ITB has also been used in a variety of less common conditions in which spasticity can be a significant feature, including transverse myelitis, amyotropic lateral sclerosis, brain and spinal cord tumors, ${ }^{9}$ Huntington disease, and holoprosencephaly, ${ }^{10,11}$ among others. It has also been used in the treatment of generalized dystonia. $^{12-14}$

The delivery devices for ITB therapy, the subject of this review, are implantable and programmable (subcutaneous) pump reservoirs with tunneled catheters extending into the spinal canal for continuous delivery of baclofen into the intrathecal space. This allows the drug to be concentrated in receptors that are just under the surface of the spinal cord at different spinal cord levels, depending on the location of the catheter tip. ${ }^{15,16}$ Despite continued advancements in manufacturing and surgical technique, ITB device-related complications are still relatively common and can result in a potentially critical withdrawal syndrome. In the event of suspected pump malfunction, radiologic assessment of the delivery system (pump and associated catheter) is an important adjunct to the clinical evaluation for identifying a cause of system malfunction and the possible necessity for surgical revision. This article reviews imaging techniques for anatomic and functional assessment of ITB pump systems, including plain radiography and nuclear scintigraphy as well as fluoroscopy and CT per-

From the Neuroradiology Division (A.C.M., A.V., S.K.M., D.J.O.), Department of Radiology, and Department of Physical Medicine and Rehabilitation (M.A.F., R.N.A.), University of Michigan Medical Center, Ann Arbor, Michigan.

Please address correspondence to Douglas J. Quint, MD, B1D520B, Neuroradiology, Box 30, Department of Radiology, University of Michigan Medical Center, 1500 East Medical Center Dr., Ann Arbor, Ml 48109-0030; e-mail: djquint@umich.edu

Indicates open access to non-subscribers at www.ajnr.org

DOI 10.3174/ajnr.A2211 formed during/after contrast injection into the pump-catheter system. Immediate postsurgical complications are not reviewed.

\section{Background}

\section{Baclofen}

Spasticity, a common result of upper motor neuron injury, is thought to result, in part, from inadequate release of the inhibitory neurotransmitter GABA in the dorsal horn regions of the spinal cord, where upper motor neurons modulate lower motor neuron monosynaptic and polysynaptic reflex arcs (by GABA-mediated inhibition). The unchecked excitatory neurotransmitter (eg, glutamate) then leads to spasticity. Baclofen (4-amino-3 [p-chlorophenyl] butyric acid) is a structural analog to GABA that binds pre- and postsynaptic GABA B receptors in the central nervous system, mimicking the synaptic inhibitory effects of GABA by blocking calcium influx. This inhibitory effect decreases muscle tone and suppresses muscle spasm. ${ }^{17,18}$ Intrathecal administration of baclofen exhibits pharmacologic action selective for the spinal cord, ${ }^{19,20}$ because the subarachnoid concentration of intrathecally injected baclofen diminishes in the cranial direction along the neuraxis, with a lumbar/cisternal ratio of approximately $4: 1{ }^{21}$ Dosing can be titrated to maximize muscle spasm control while minimizing systemic side effects. ${ }^{22}$

\section{Pump Characteristics}

ITB is delivered by a programmable pump surgically implanted in the wall of the anterolateral abdomen that gives rise to a silicone rubber catheter that is tunneled subcutaneously around the patient's side to the midline lower back where it extends anteriorly to the spinal canal to enter the intrathecal compartment at the midlumbar level (Fig 1). The final location (ie, spinal level) of the catheter tip in the thecal sac is dependent on the clinical indication for the pump (see below). The pumps used at our institution are the SynchroMed II and SynchroMed EL (Medtronic, Minneapolis, Minnesota), which are disk-shaped and made of titanium, approximately 3 inches in diameter and 1 inch thick (Figs 2 and 3 ). They have a central port for percutaneous drug administration into a reservoir as well as a peripheral accessory catheter-access port for diagnostic troubleshooting. Placement of the catheter tip itself, after it has been introduced into the CSF space via a pos- 


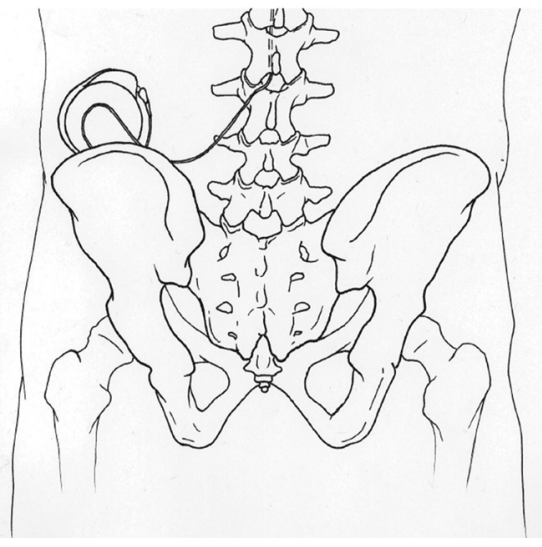

Fig 1. Illustration depicting an intrathecal baclofen pump implanted in the anterolateral abdominal wall with a catheter coursing subcutaneously around the patient to enter the spinal canal.

terior midline approach (see above) (a paramedian oblique approach to the spine for the insertion of the catheter has also been reported ${ }^{23}$ ), depends on the treatment indication. Placement of the tip of the intrathecal catheter at the T1-2 level for spastic quadriplegia, the T6-10 level for spastic diplegia, and in the midcervical region for dystonia has been suggested, ${ }^{24}$ though techniques vary. ${ }^{13}$ The typical SynchroMed pump battery life is 5-7 years. ${ }^{22}$ Despite continuing evolution in pump technology and implantation techniques, complications and pump malfunctions still occur.

\section{Pump Malfunction}

Baclofen "withdrawal" syndrome is a potentially life-threatening event characterized by fever, hallucinations, and rebound spasticity as well as autonomic instability, mental status changes, seizure, and rhabdomyolysis in more severe cases. ${ }^{25-27}$ The symptoms can overlap other life-threatening clinical scenarios, including sepsis, intracerebral hemorrhage, seizure, and drug toxicity, placing a premium on the rapid identification and correction of baclofen withdrawal to appropriately guide patient care. Disruption/malfunction of the pump-catheter system is a common cause of baclofen withdrawal and can result in a spectrum of symptoms, from simple worsening of a patient's spasticity to, in the event of abrupt cessation of intrathecal baclofen delivery, fulminant withdrawal symptoms resembling neuroleptic malignant syndrome. ${ }^{25}$

Reported rates of ITB pump-catheter system complications have varied because there is a great deal of diversity with respect to patient follow-up intervals and treatment indications. ${ }^{7,10,11,28-30}$ Long-term follow-up studies have suggested an approximately $37 \%-55 \%$ rate of pump and/or catheter malfunction..$^{7,29,31}$

The most common complications are catheter-related, occurring in $\leq 40 \%$ of patients with ITB pumps. ${ }^{7,31}$ Rates as low as $4 \%$, however, have also been reported in 1-year follow-up. ${ }^{11}$ Catheter-related complications include disconnection from the pump (6\%-10\%); leak resulting from breakage, cut, or puncture $(5 \%-16 \%)$; catheter-tip migration, dislocation, or dislodgment $(3 \%-11 \%)$; and kink or occlusion of the catheter (2\%-20\%). ${ }^{7,10,28-32}$

Pump malfunction occurs in $\leq 14 \%$ of patients, ${ }^{7,31}$ though some reports have described significantly lower rates. ${ }^{11}$
Pump-related complications include rotor malfunction, reservoir depletion, programming/software malfunctions, ${ }^{33,34}$ and frank baclofen leakage from the pump, which can lead to subcutaneous fluid collection. ${ }^{28}$ Complications occur more frequently in children ${ }^{22,24,35}$ and have been reported to be reduced when the pump is placed subfascially in that patient group. $^{23}$

In the event of suspected pump malfunction, Bardutzky et $\mathrm{al}^{33}$ suggest the following diagnostic algorithm for determining the cause of the malfunction: First, check the pump programming and reservoir status by interrogating the appropriate pump hardware and software. Second, obtain AP and lateral abdominal radiographs, which can be useful in identifying catheter dislodgment or disconnection. ${ }^{36}$ Radiographs should also be obtained with a programmed $90^{\circ}$ (SynchroMed EL) or $120^{\circ}$ (SynchroMed II) angular rotation to exclude rotor dysfunction-the so-called "rotor test" for the SynchroMed EL device or the "roller study" for the SynchroMed II system (see below). ${ }^{33,34}$ In the event of overt withdrawal symptoms, a bolus dose of baclofen should be programmed or given via lumbar puncture. Finally, intrathecally approved (eg, myelographic) contrast material (such as Omnipaque $180 \mathrm{mg} \%$, iohexol; GE Healthcare, Milwaukee, Wisconsin) can be injected through the accessory pump port to identify leaks, though the utility of contrast injection has been disputed. ${ }^{37}$ Injection of contrast into the catheter via the accessory pump port should always be preceded by aspiration of $2-3 \mathrm{~mL}$ of fluid from the accessory pump port (which will clear any residual baclofen from the accessory port and the catheter) to avoid acute baclofen overdose. In addition to this approach, CT scanning and radioisotopic evaluations can be performed for more detailed evaluation.

\section{Imaging Evaluation}

\section{Radiography and Fluoroscopy}

There is a paucity of evidence directly evaluating the ability of plain films alone to reliably identify pump- and catheter-related complications necessitating surgical revision. Nevertheless, several of the most common complications, including catheter-related problems such as kinking (Fig 4), migration, discontinuity (Fig 5), and other more obvious dislodgments, can often be identified by plain films. For this reason, plain radiography is typically the initial approach to imaging evaluation of suspected pump-catheter system malfunction. Information with respect to intrinsic pump function (eg, pump rotor/roller function) can also be obtained if radiographs are performed both before and after a programmed rotation of the rotor. An angular rotation of $90^{\circ}$ or $120^{\circ}$ is expected for the SynchroMed EL and SynchroMed II devices, respectively. Failure to observe rotor or roller movement usually indicates a rotor/roller malfunction, but occlusion of the catheter (eg, by a catheter kink) can also cause a rotor/roller stall. Exposure to an external magnetic field as with MR imaging can also affect rotor/roller motion (though the rotor should spontaneously restart once the magnetic field is removed). ${ }^{34}$

The combination of a standard abdominal radiograph, AP and lateral lumbar spine radiographs, and an AP thoracic spine radiograph usually fully visualizes the entire pump and catheter system, ${ }^{34}$ though proper imaging technique is crucial 


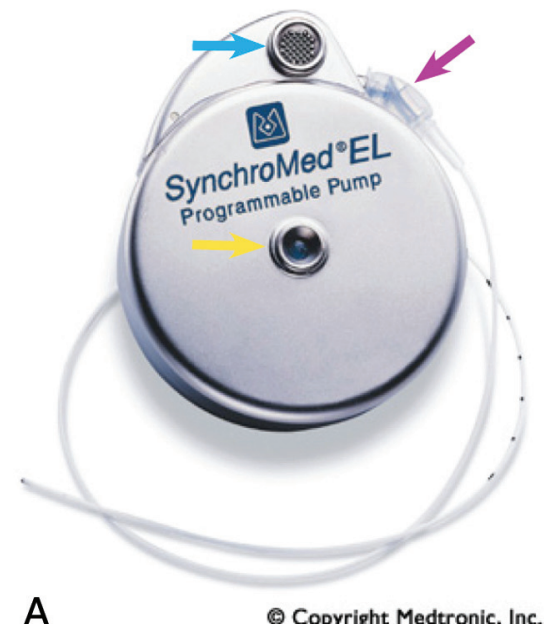

A

๑) Copyright Medtronic, Inc.
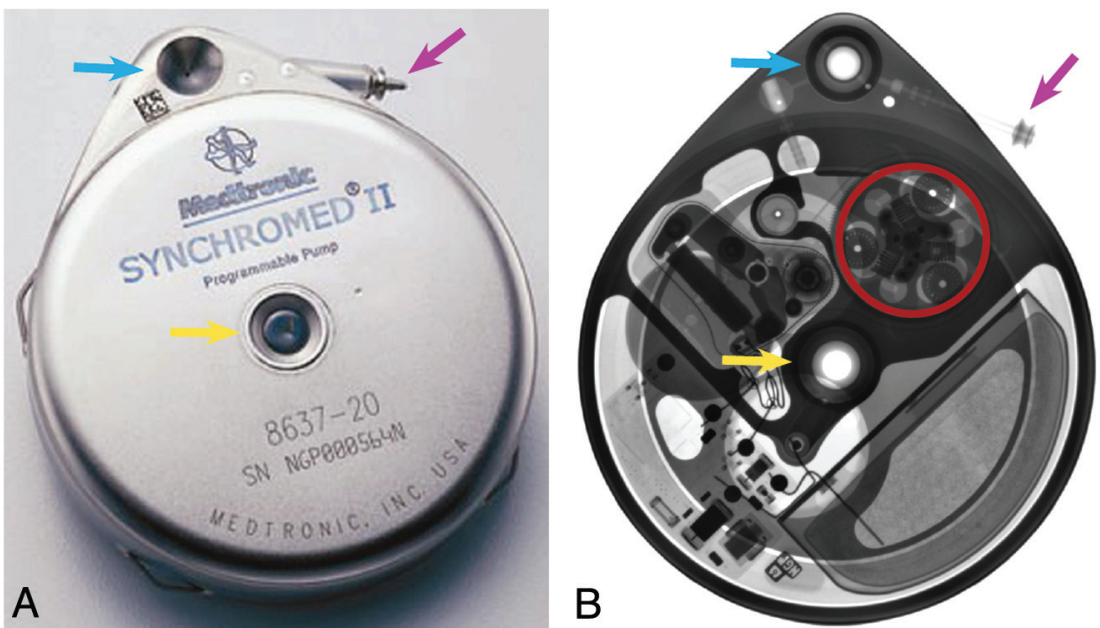

Fig 2. Photographic $(A)$ and radiographic $(B)$ representations of the SynchroMed model EL intrathecal baclofen pump depicting the pump rotor (red ring), reservoir port (yellow arrow), catheter-access port (blue arrow), and the pump connector (magenta arrow). (Copyrighted images reprinted with permission of Medtronic, Inc.)
Fig 3. Photographic $(A)$ and radiographic $(B)$ representations of the SynchroMed model II intrathecal baclofen pump depicting the pump roller (red ring), reservoir port (yellow arrow), catheter-access port (blue arrow), and pump connector (magenta arrow)

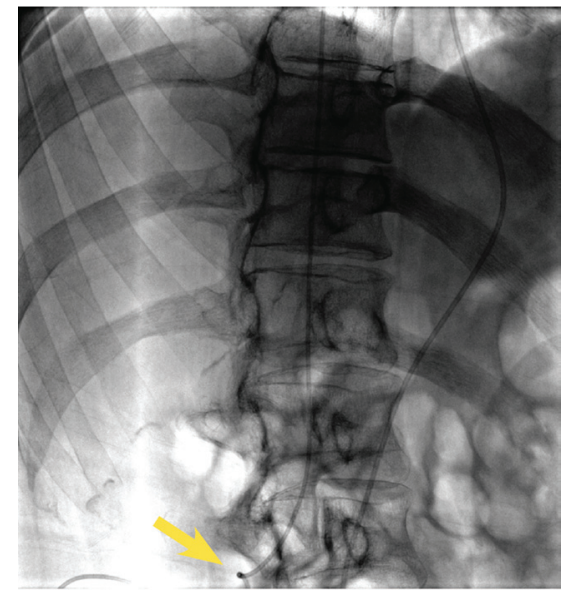

Fig 4. An AP radiograph demonstrates a kinked/folded catheter (yellow arrow) within the subcutaneous tissue.

with respect to these plain radiographs to assess the entire subcutaneous course of the tunneled catheter. Plain films can be inconclusive, however, because simple anatomic visualization of the catheter and pump fails to provide information about catheter patency, occlusion, ${ }^{38}$ or leaks.

Fluoroscopic studies are the next step if plain films are not diagnostic. As mentioned above, $2-3 \mathrm{~mL}$ of fluid should first be aspirated from the accessory port to avoid rapidly deliver- ing the residual catheter baclofen to the patient during contrast injection, which can cause a life-threatening baclofen overdose. ${ }^{39}$ If CSF is successfully aspirated and the patient's symptoms are relatively mild, programming an intrathecal baclofen bolus through the pump-catheter system as a therapeutic trial is reasonable. ${ }^{34}$ If the patient's symptoms are severe or there is no response to a baclofen bolus, fluoroscopy during contrast injection through the accessory port is indicated. Disconnection of the catheter from the pump (Fig 6), macroscopic perforations (Fig 7) and leaks (Fig 8), as well as catheter-tip dislodgments or migration can sometimes be visualized during such injection studies when plain films are unrevealing. Viewing the injected catheter under fluoroscopy during positional changes of the patient can also be beneficial if there is any historical suggestion that symptoms are position-dependent (ie, spasticity is more pronounced when the patient has been supine for a prolonged period of time, etc).

There are several limitations to fluoroscopy, and a high false-negative rate has been suggested. In particular, there can be a limited ability to detect catheter-tip loculations, catheter migrations, microscopic perforations/leaks, and some larger leaks. ${ }^{34,37}$ It is also important to check behind the pump for contrast accumulation because collections in this space can be missed. Injection of contrast into the pump reservoir for evaluation of pump function is usually not helpful due to the di- 

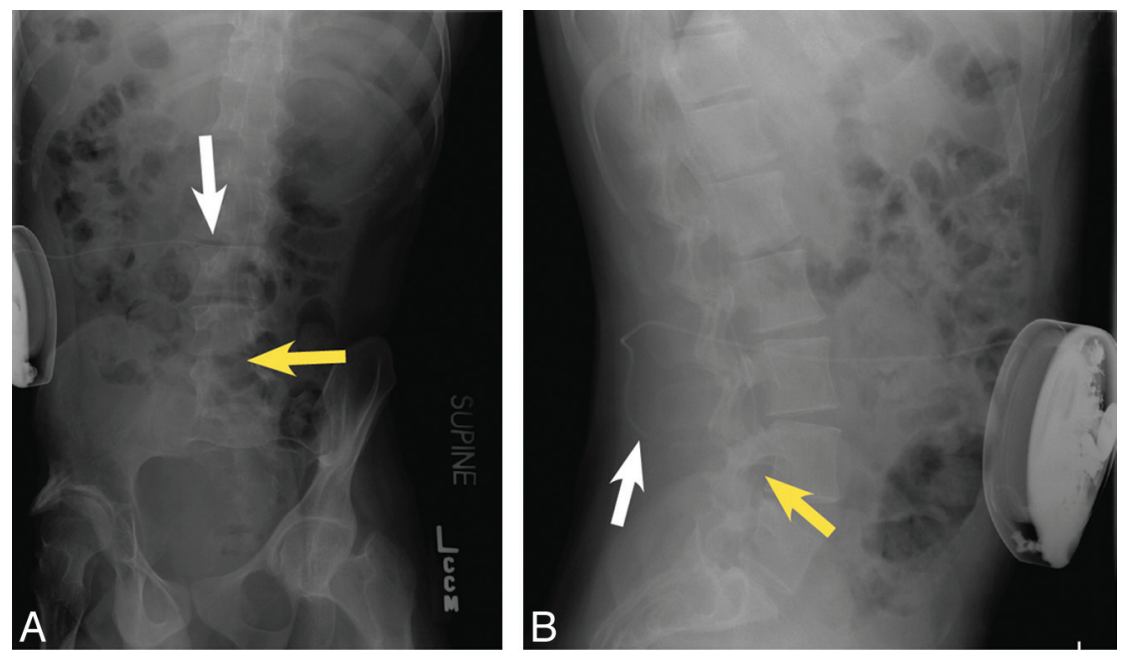

Fig 5. $\mathrm{AP}(A)$ and lateral $(B)$ radiographs demonstrating a discontinuous segment of the catheter, with broken catheter ends in the subcutaneous tissue of the lower back (white arrow) and the spinal canal (yellow arrow).
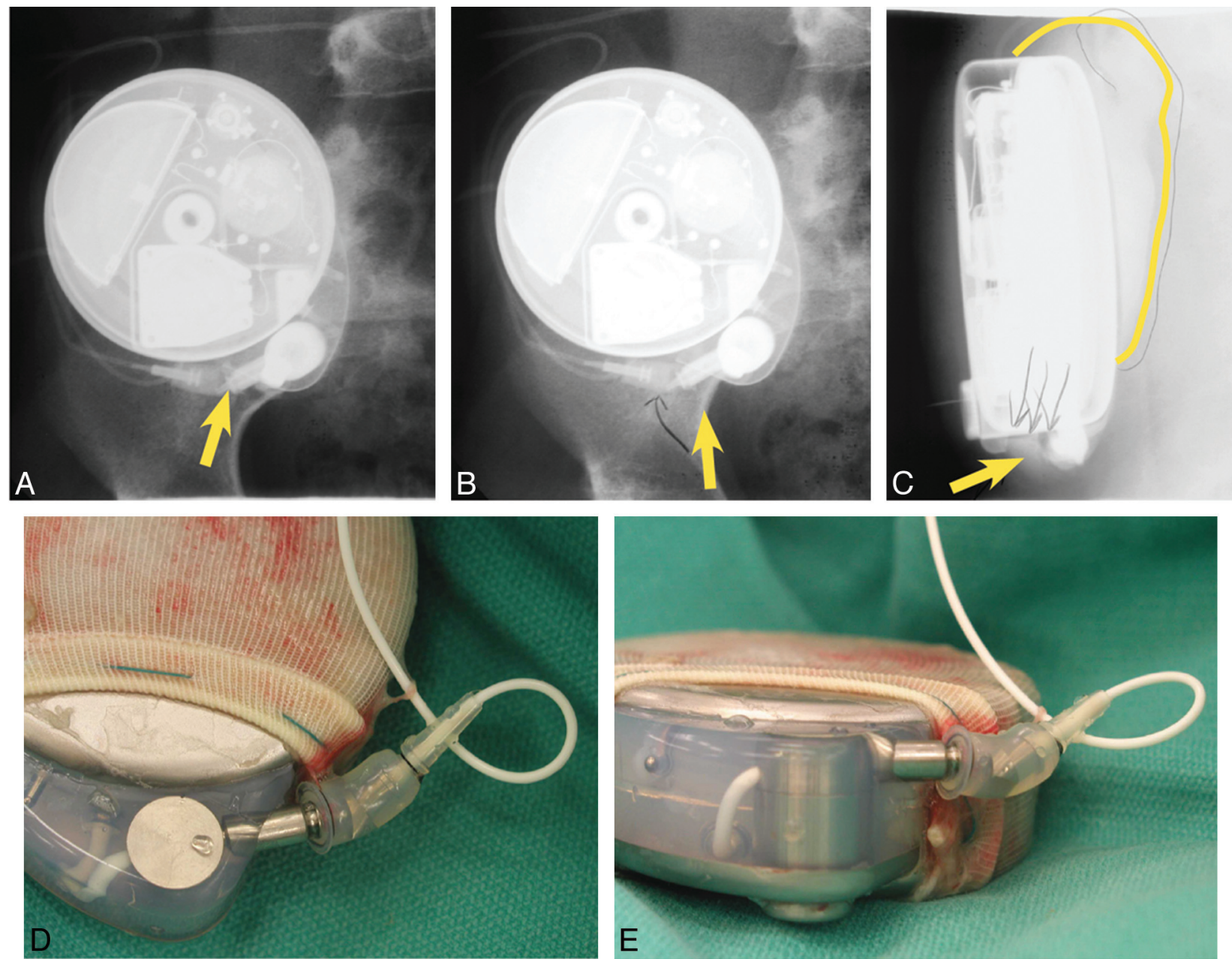

Fig 6. A, Initial fluoroscopic spot image (A) demonstrating disconnection at the pump connector (arrow). B, A small amount of contrast extravasation (yellow arrow) is seen after injection of contrast via the catheter-access port (fluoroscopic spot image). C, A lateral fluoroscopic spot image better demonstrates contrast extravasation at the connector (yellow arrow) and reveals a collection of pooled contrast (yellow outline) posterior to the pump. $D$ and $E$, Photographs demonstrate the disconnection at the connector after surgical explantation.

lutional ratio and slow infusion rate of the system. ${ }^{37,38} \mathrm{CT}$ appears to be more sensitive than fluoroscopy in identifying some of these abnormalities (see below).

\section{CT}

To our knowledge, there is scant literature regarding the use of CT in the evaluation of ITB pump malfunction. Our institu- tional experience, however, suggests that CT-particularly postcontrast (ie, postinjection of contrast material through the accessory pump port) CT-can be a useful adjunct to fluoroscopy performed during contrast injection for improved identification and characterization of leaks and fluid collections (Figs $8-10) .{ }^{40}$ Cross-sectional imaging can also aid in visualizing the location of the catheter tip in the spinal canal 

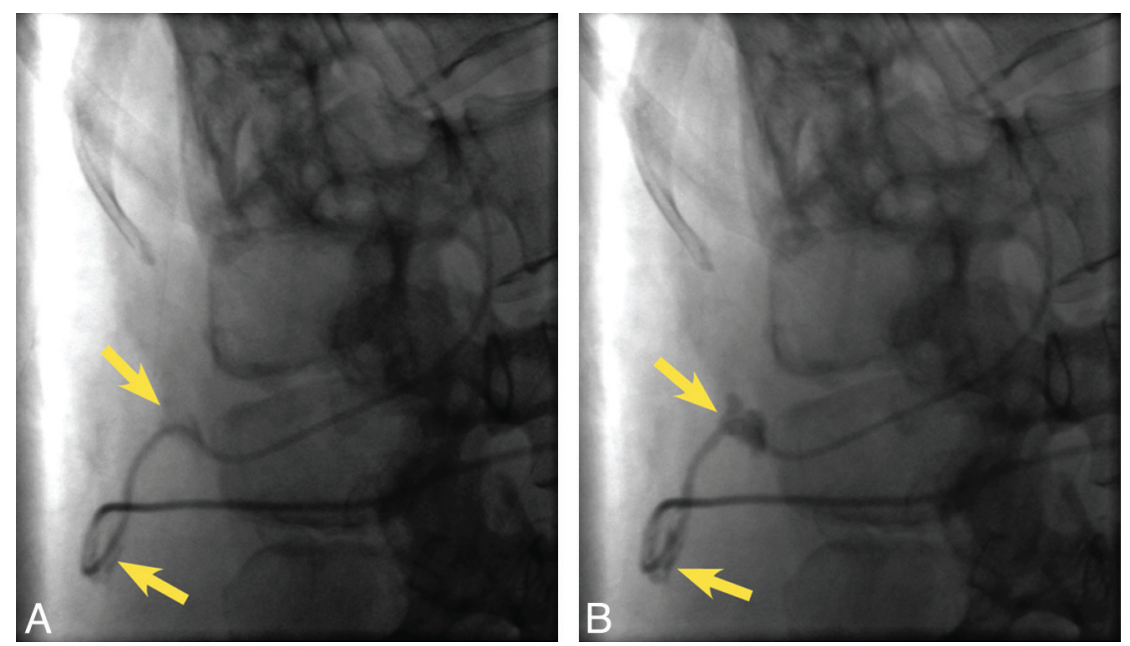

Fig 7. Lateral fluoroscopic spot image $(A)$ reveals extravasating contrast (yellow arrows) from an apparently intact catheter. Further extravasation (arrows) is demonstrated during continued injection $(B)$, consistent with catheter perforation.
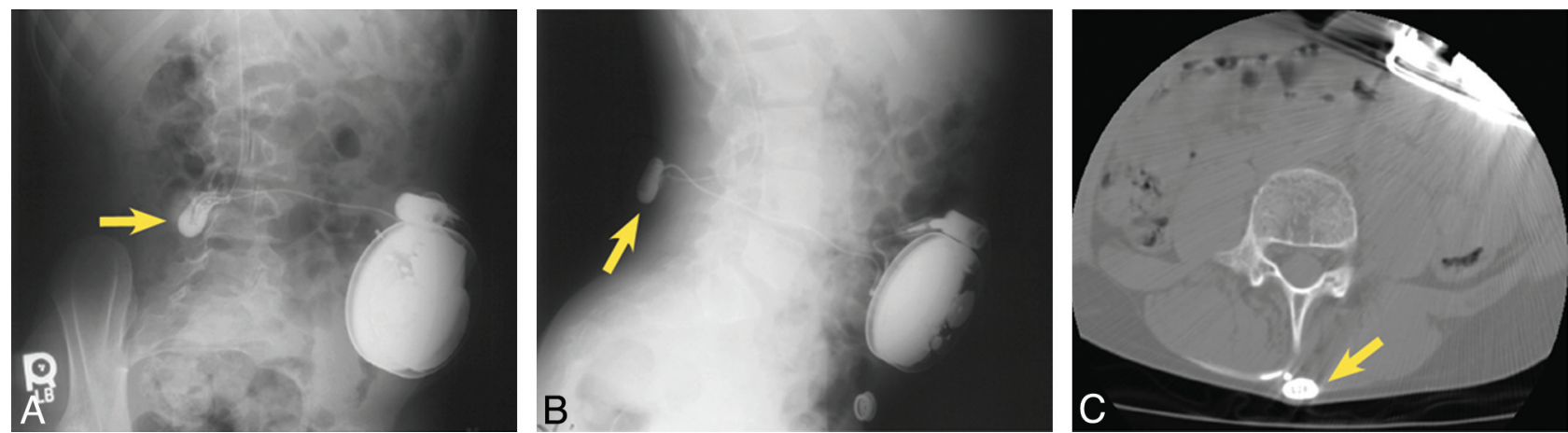

Fig 8. $\mathrm{AP}(A)$ and lateral $(B)$ radiographs as well as an axial $\mathrm{CT}(C)$ image show extravasated contrast material (yellow arrows) surrounding the catheter connector in the subcutaneous tissues of the mid-lower back, where it turns anteriorly toward the spinal canal.

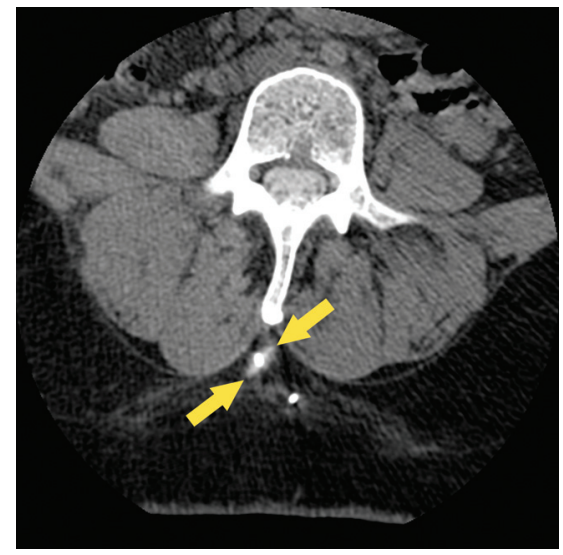

Fig 9. Axial CT image demonstrates an extraluminal contrast collection (yellow arrows) adjacent to an apparently intact catheter. This contrast extravasation was not identified at fluoroscopic evaluation performed during contrast injection.

(ie, within the intrathecal sac) when plain film findings are equivocal (Fig 11). ${ }^{34,41}$ Two-to-three milliliters of myelographic contrast agent can be injected through the accessory pump port (after successful CSF aspiration) and should be performed while the patient is on the CT table to ensure that the contrast is not overdiluted in the CSF when the images are acquired. ${ }^{34}$ At our institution, we inject as much as $5-10 \mathrm{~mL}$ of thecal sac-compatible contrast material while observing the entire pump-catheter system fluoroscopically and then immediately obtain a CT scan of any areas of concern. Dependent layering of contrast material in the IT space adjacent to the catheter tip suggests a normal study finding. Contrast collection in the subcutaneous, subdural, or epidural spaces suggests leak or tip migration. Limited accumulation of contrast material near the catheter tip with the contrast not appropriately layering in the IT space may suggest focal loculations within the subarachnoid space in the region of the catheter tip. ${ }^{34}$

\section{Nuclear Scintigraphy}

Radionuclide flow studies of the ITB delivery system may be indicated if a more complete functional evaluation of the device is warranted or if prior imaging findings are inconclusive. The injection of radioisotopes into the pump reservoir allows the pump system to be evaluated in its native state of infusion. ${ }^{111}$ In DTPA is typically the preferred radiopharmaceutical due to its long half-life, which allows radioactivity to be monitored for $\leq 7$ days as it travels through the catheter and into the subarachnoid space. ${ }^{38}{ }^{111}$ In DTPA is injected at a dose of 0.5$0.6 \mathrm{mCi}$ into the reservoir without interrupting the delivery of baclofen, ${ }^{38,42,43}$ or the reservoir can be emptied and refilled with radiopharmaceutical solution. ${ }^{37}$

The ideal methodologic approach for scintigraphic evaluation of suspected ITB pump malfunction still remains relatively undefined, as do the normal flow patterns and diagnostic criteria for abnormal study findings. ${ }^{38}$ In a series of 23 studies on 19 patients, Stinchon et $\mathrm{al}^{43}$ defined a normally functioning pump as one for which radioactivity was observed in the subarachnoid space by 72 hours. Lack of radioactivity 

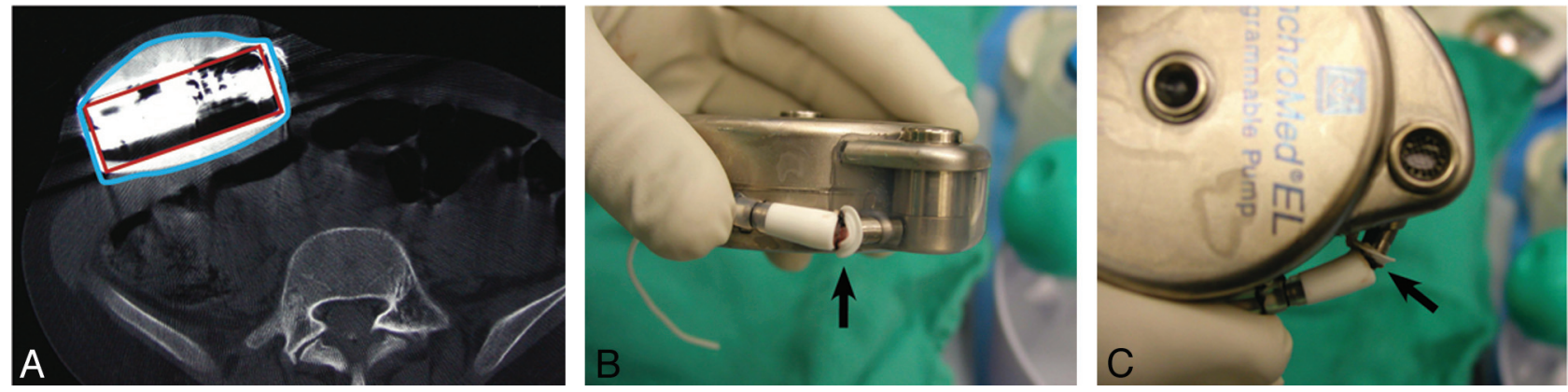

Fig 10. $A$, An axial CT image reveals a pocket of extravasated contrast (blue outline) both anterior and posterior to the pump (red outline) in the anterior abdominal wall. $B$ and $C$, Photographs taken after surgical explantation demonstrate breakage at the connector (black arrows).

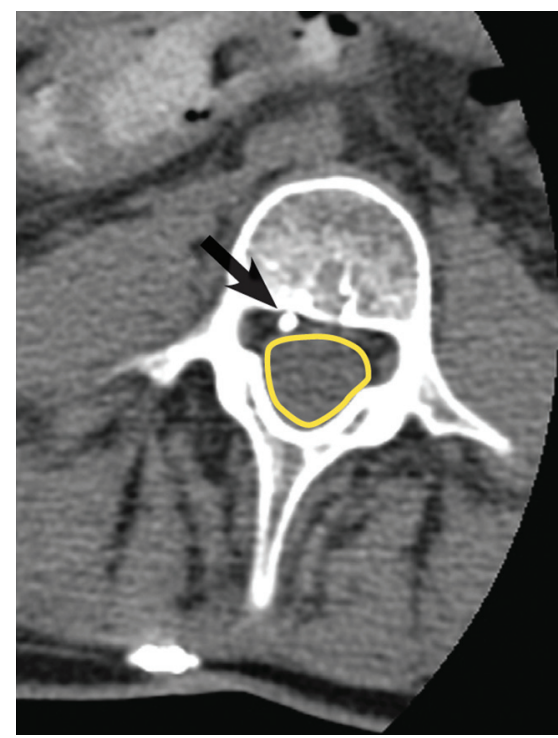

Fig 11. An axial noncontrast CT image clearly shows the catheter (black arrow) outside the thecal sac (yellow outline) in the epidural space.

distal to the pump reservoir suggested mechanical failure or disruption in the pump-catheter connection and indicated the need for a simple pump rotor test if it had not already been performed. Radioactivity reaching a point in the catheter but not progressing to the subarachnoid space was suggestive of a catheter kink or occlusion (suggesting the need for surgery) (Fig 12), while radiopharmaceutical accumulation at the site of occlusion was indicative of a leak.

The normal transit time to the basal cisterns (ie, the subarachnoid space at the base of the brain) continues to be a subject of controversy, but most authors agree that radioactivity should be observed in the basal cisterns of the brain within $48-72$ hours of radiopharmaceutical injection in a normally functioning pump system. ${ }^{34,42-44}$ As with some of the other techniques of ITB pump evaluation, scintigraphy has limited sensitivity for identifying the exact cause of system failure. Specifically, scintigraphy poorly differentiates intrinsic pump malfunction from high-grade obstruction blocking egress of baclofen from the pump, poorly delineates the specific causes of catheter obstruction, and poorly delineates catheter microfractures. ${ }^{43}$

\section{Future Directions}

Despite expanding use of ITB pumps, device-related complications continue to be relatively common. As the population

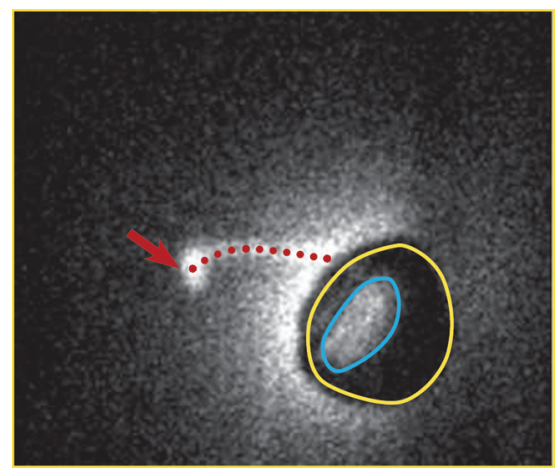

Fig 12. Scintigraphic image obtained 48 hours after injection of $1-\mathrm{mCi}{ }^{111}$ In DTPA into the medication reservoir reveals nonpatency of the catheter system with no intrathecal contrast visualized. The area of photopenia represents the position of the pump (yellow outline). Radioactivity within the pump represents the medication reservoir (blue outline). Radiopharmaceutical is observed within the proximal catheter (red dotted line) and ends abruptly (red arrow). Note that the etiology of the nonpatency of the catheter cannot be determined from this study.

with implanted ITB pumps ages and pumps are placed in increasingly disabled patients, the complexity of imaging evaluation can be expected to increase in parallel with difficulties in the surgical placement and/or revision of these systems. Furthermore, as the duration of ITB therapy increases and patients are re-evaluated in long-term follow-up, novel complications related to chronic ITB use may be recognized. Advanced functional and cross-sectional imaging techniques can be expected to be increasingly used for better characterization of complex pump- and catheter-related malfunctions. Inflammatory masses or granulomas at the catheter tip, for example, though more commonly seen with chronic opiate infusions, have been described with ITB infusion alone ${ }^{45}$ and appear to be best identified and characterized by T2-weighted MR imaging, with post-catheter-injection or postmyelography CT as an imaging option. In patients receiving combined opiate and baclofen infusion, the risk of developing a granuloma with chronic infusion can be expected to be higher. The use of MR imaging, which is not contraindicated for patients with ITB pumps, requires further evaluation for use in the setting of possible pump malfunction with a catheter-tip region lesion suspected of causing an obstruction. With respect to advancing nuclear medicine techniques, O'Connell et $\mathrm{al}^{44}$ published a case report using Tc99m DTPA for evaluation of suspected ITB pump malfunction, suggesting that complete evaluation of pump function and catheter patency could be conducted in 1 hour with superior image quality, though the 
pump reservoir had to be first emptied with their technique. Scintigraphy with Tc99m DTPA still requires further evaluation to establish its utility for ITB pump evaluation.

\section{Conclusions}

Use of intrathecal baclofen therapy is becoming increasingly more widespread, and device-related malfunctions are common and can lead to life-threatening symptoms due to acute baclofen withdrawal. For evaluation of suspected pump-catheter dysfunction, plain radiography of the pump-catheter system and a programmed pump rotor/roller evaluation are the first imaging tests that should be performed, though it is recognized that these tests fail to evaluate catheter patency, occlusion, or leaks not associated with catheter discontinuities. Contrast injection through the pump-catheter system under fluoroscopy can identify many catheter-related complications but still can miss microscopic catheter perforations/leaks, catheter-tip loculations, or local catheter-tip migrations. CT performed during/after such contrast material injection appears to be a more sensitive test to identify and characterize such complications. Radionuclide studies are also helpful to evaluate pump function, catheter disconnections, occlusions, and leaks, but they are relatively insensitive to the exact cause of the pump-catheter system malfunction in any 1 case and are also expensive and can require $\geq 2-3$ days for a complete evaluation. Future possible imaging techniques for evaluation of these patients may include MR imaging for identifying catheter-tip granulomas.

Increasingly severe patient disability and chronicity of ITB use may necessitate more combined-technique approaches to the evaluation of ITB pump systems in the future, and costeffective imaging triage algorithms will need to be refined as chronic complications are better characterized.

\section{References}

1. Penn RD, Kroin JS. Intrathecal baclofen alleviates spinal cord spasticity. Lancet 1984;1:1078

2. Dralle D, Muller H, Zierski J, et al. Intrathecal baclofen for spasticity. Lancet $1985 ; 2: 1003$

3. Gilmartin R, Bruce D, Storrs BB, et al. Intrathecal baclofen for management of spastic cerebral palsy: multicenter trial. J Child Neurol 2000;15:71-77

4. Van Schaeybroeck P, Nuttin B, Lagae L, et al. Intrathecal baclofen for intractable cerebral spasticity: a prospective placebo-controlled, double-blind study. Neurosurgery 2000;46:603-09, discussion 609-12

5. Becker R, Alberti O, Bauer BL. Continuous intrathecal baclofen infusion in severe spasticity after traumatic or hypoxic brain injury. J Neurol 1997; 244:160-66

6. Becker R, Benes L, Sure U, et al. Intrathecal baclofen alleviates autonomic dysfunction in severe brain injury. J Clin Neurosci 2000;7:316-19

7. Penn RD. Intrathecal baclofen for spasticity of spinal origin: seven years of experience. J Neurosurg 1992;77:236-40

8. Meythaler JM, Guin-Renfroe S, Brunner RC, et al. Intrathecal baclofen for spastic hypertonia from stroke. Stroke 2001;32:2099-109

9. Stempien L, Tsai T. Intrathecal baclofen pump use for spasticity: a clinical survey. Am J Phys Med Rehabil 2000;79:536-41

10. Guillaume D, Van Havenbergh A, Vloeberghs M, et al. A clinical study of intrathecal baclofen using a programmable pump for intractable spasticity. Arch Phys Med Rehabil 2005;86:2165-71

11. Albright AL, Awaad Y, Muhonen M, et al. Performance and complications associated with the SychroMed 10-ml infusion pump for intrathecal baclofen administration in children. J Neurosurg 2004;101(1 suppl):64-68

12. Albright AL, Barry MJ, Fasick $P$, et al. Continuous intrathecal baclofen infusion for symptomatic generalized dystonia. Neurosurgery 1996;38:934-38, discussion 938-39

13. Albright AL, Barry MJ, Shafton DH, et al. Intrathecal baclofen for generalized dystonia. Dev Med Child Neurol 2001;43:652-57

14. Motta F, Antonello CE, Stignani C. Upper limbs function after intrathecal baclofen therapy in children with secondary dystonia. J Pediatr Orthop 2009;29:817-21

15. Grabb PA, Guin-Renfroe S, Meythaler JM. Midthoracic catheter tip placement for intrathecal baclofen administration in children with quadriparetic spasticity. Neurosurgery 1999;45:833-36, discussion 836-37

16. McCall TD, MacDonald JD. Cervical catheter tip placement for intrathecal baclofen administration. Neurosurgery 2006;59:634-40

17. Macdonell RA, Talalla A, Swash M, et al. Intrathecal baclofen and the H-reflex. J Neurol Neurosurg Psychiatry 1989;52:1110-12

18. Muller H, Zierski J, Dralle D, et al. The effect of intrathecal baclofen on electrical muscle activity in spasticity. J Neurol 1987;234:348-52

19. Albright AL. Intrathecal baclofen in cerebral palsy movement disorders. J Child Neurol 1996;11(suppl 1):S29-35

20. Gracies JM, Nance P, Elovic E, et al. Traditional pharmacological treatments for spasticity. Part II. General and regional treatments. Muscle Nerve Suppl 1997;6:S92-120

21. Kroin JS, Ali A, York M, et al. The distribution of medication along the spinal canal after chronic intrathecal administration. Neurosurgery 1993;33:226-30, discussion 230

22. Brennan PM, Whittle IR. Intrathecal baclofen therapy for neurological disorders: a sound knowledge base but many challenges remain. Br J Neurosurg 2008;22:508-19

23. Albright AL, Turner M, Pattisapu JV. Best-practice surgical techniques for intrathecal baclofen therapy. J Neurosurg 2006;104(4 suppl):233-39

24. Vender JR, Hester S, Waller JL, et al. Identification and management of intrathecal baclofen pump complications: a comparison of pediatric and adult patients. J Neurosurg 2006;104(1 suppl):9-15

25. Kao LW, Amin Y, Kirk MA, et al. Intrathecal baclofen withdrawal mimicking sepsis. J Emerg Med 2003;24:423-27

26. Dawes WJ, Drake JM, Fehlings D. Microfracture of a baclofen pump catheter with intermittent under- and overdose. Pediatr Neurosurg 2003;39:144-48

27. Alden TD, Lytle RA, Park TS, et al. Intrathecal baclofen withdrawal: a case report and review of the literature. Childs Nerv Syst 2002;18:522-25. Epub 2002 Jul 23

28. Plassat R, Perrouin Verbe B, et al. Treatment of spasticity with intrathecal baclofen administration: long-term follow-up, review of $\mathbf{4 0}$ patients. Spinal Cord 2004;42:686-93

29. Coffey JR, Cahill D, Steers W, et al. Intrathecal baclofen for intractable spasticity of spinal origin: results of a long-term multicenter study. J Neurosurg 1993;78:226-32

30. Gooch JL, Oberg WA, Grams B, et al. Complications of intrathecal baclofen pumps in children. Pediatr Neurosurg 2003;39:1-6

31. Fluckiger B, Knecht H, Grossmann S, et al. Device-related complications of long-term intrathecal drug therapy via implanted pumps. Spinal Cord 2008;46:639-43

32. Albright AL, Gilmartin R, Swift D, et al. Long-term intrathecal baclofen therapy for severe spasticity of cerebral origin. J Neurosurg 2003;98:291-95

33. Bardutzky J, Tronnier V, Schwab S, et al. Intrathecal baclofen for stiff-person syndrome: life-threatening intermittent catheter leakage. Neurology 2003; 60:1976-78

34. Francisco GE, Saulino MF, Yablon SA, et al. Intrathecal baclofen therapy: an update. $P M R$ 2009;1:852-58

35. Motta F, Buonaguro V, Stignani, C. The use of intrathecal baclofen pump implants in children and adolescents: safety and complications in 200 consecutive cases. J Neurosurg 2007;107( 1 suppl):32-35

36. Shirley KW, Kothare S, Piatt JH Jr, et al. Intrathecal baclofen overdose and withdrawal. Pediatr Emerg Care 2006;22:258-61

37. Le Breton F, Daviet JC, Monteil J, et al. Radioisotopic control for baclofen pump catheter failure. Spinal Cord 2001;39:283-85

38. Pak S, Jallo GI, Biser A, et al. Indium-111 diethylene-triamine-pentaacetic acid scintigraphy in the evaluation of function and patency of baclofen intrathecal infusion systems. Neurosurg Focus, 2007;23:E17

39. Yeh RN, Nypaver MM, Deegan TJ, et al. Baclofen toxicity in an 8-year-old with an intrathecal baclofen pump. J Emerg Med 2004;26:163-67

40. Li TC, Chen MH, Huang JS, et al. Catheter migration after implantation of an intrathecal baclofen infusion pump for severe spasticity: a case report. Kaohsiung J Med Sci 2008;24:492-97

41. Pasquier Y, Cahana A, Schnider A. Subdural catheter migration may lead to baclofen pump dysfunction. Spinal Cord 2003;41:700-02

42. Rosenson AS, Ali A, Fordham EW, et al. Indium-111 DTPA flow study to evaluate surgically implanted drug pump delivery system. Clin $\mathrm{Nucl} \mathrm{Med}$ 1990;15:154-56

43. Stinchon JF, Shah NP, Ordia J, et al. Scintigraphic evaluation of intrathecal infusion systems: selection of patients for surgical or medical management. Clin Nucl Med 2006;3:1-4

44. O'Connell M, Wong TZ, Forkheim KE, et al. Comparison of Tc99m-DTPA and indium-111 DTPA studies of baclofen pump function. Clin Nucl Med 2004;29:578-80

45. Deer TR, Raso LJ, Garten TG. Inflammatory mass of an intrathecal catheter in patients receiving baclofen as a sole agent: a report of two cases and a review of the identification and treatment of the complication. Pain Med 2007;8:259-62 